469 PYNAMICS OF ALTERED ILEAL TRANS PORT IN VIRAL DIARRHEA. Ross W. Shepherd, Dan G. Butler, D. Grant Ga1l and Univ.Toronto, Dept.Clin.Stud,, Ont.Vet.Coll., Univ.Gue1ph, Ont.Canada. We studied active ileal iontransport invitro in piglets with acute diarrhea caused by transmissible gastroenteritis(TGE)virus. This invasive enteritis, similar to infantile human rotavirus enteritis, is thought to affect mainly upper bowel. In shortcircuited ileum, $40 \mathrm{hrs}$ after infection when diarrhea severe, net $\mathrm{Na}^{+}$and $\mathrm{Cl}^{-}$flux decreased under basal conditions, failed to respond to glucose $30 \mathrm{mM}$. Virus antigen was detected by immune fluorescence in jejunum but also in ileal epithelium at 12 and 18 hrs; shed by $24 \mathrm{hrs}$ and did not reappear. At $40 \mathrm{hrs}$, in ileum, villi shortened, crypts deepened, cell transit accelerated and enzymes of villus cells resembled normal crypt cells ( $\downarrow$ thymidine $k$ inase (TK), I sucrase(S) and $\{\mathrm{Na}-\mathrm{K}-\mathrm{ATPase})$. We conclude that ion trans port in ileum, as in jejunum can be disturbed inviral enteritis, that these abnormalities result from viral invasion of the ileum, associated not with direct viral damage but with impaired enterocyte differentiation. Events in ileum, a consequence of direct infection probably not of reinfection by virus shed from \begin{tabular}{|l|l|l|l|l|l} 
proximal regions, are important determinants of viral diarrhea. \\
\hline Ilea1 & $\mathrm{Na}\left(\mathrm{Eq} / \mathrm{cm}^{2} \mathrm{hr}\right)$ & Mucosal & Cell & Enzymes (villi)
\end{tabular} Epit Epith net $\quad$ Dimensions $(\mu)$ Trans. units (mitse) bas. gluc. villi crypts (hr) $\mathrm{TK} / \mathrm{mg} \mathrm{S} / \mathrm{g}$ ATPase/g \begin{tabular}{llllll|lll} 
Control & $15 \pm 0.2$ & $3.5 \pm 0.4$ & $291 \pm 10$ & $28 \pm 6$ & 44 & 12.3 & 23.4 & 32.0
\end{tabular}

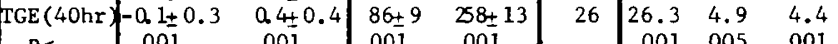

\section{EFFECT OF DIET AND LIGHT ON INTESTINAL LACTASE IN}

470 NEONATES. T.R.C. Sisson, M. Manuel, K.V.S. Rao, T. School of Medicine, Department of Pediatrics, Philadelphia. Thirty newborns were divided into 3 groups of 10 each: Gp. A, well, non-jaundiced, Gp. B jaundiced but not under phototherapy, Gp. C phototherapy for hyperbilirubinemia. Each infant was assigned randomly either cow's milk formula or a soy milk formul (lactose-free). Stools were observed daily for character, pH, and reducing substances. Lactose Tolerance Tests were done daily for 3 days - in GP. C prior to, during and after phototherapy. Birth wts. ranged from 2120 to $3870 \mathrm{gm}$ (mean $3280 \mathrm{gm}$ ) Only infants with physiologic jaundice were included.

Group A infants had normal stools, normal LTT, as did infants in Group B. In Gp. C, infants on cow's milk feeding had abnorma LTT, lowered stool pH and 3-4+ reducing substances, loose dark stools. Those in Gp. C on soy milk feeding had equivocal LTT, stools normal in color, consistency, $\mathrm{pH}$, and no reducing substances.

We conclude that hyperbilirubinemia itself does not affect lactase activity in the small intestine, but that phototherapy does cause lactase deficiency, either directly by radiation, or by the presence of bilirubin photoproducts or isomers. The use of a soy milk formula, containing sucrose rather than lactose, does not alter lactase activity significantly, but does correct CHO digestion by substituting sucrose, whose intestinal enzyme is unaffected by phototherapy. Patricia Szczepanik, Jean F. Perrault, J. Richard Hamilton, and John B. Watkins. Res. Inst. Hosp. Sick Child., Toronto, Depts. Ped, Univ. Toronto and Harvard Medical School. Boston. Mass.

We studied a 5 year old girl from early infancy with severe chronic diarrhea, steatorrhea and growth failure. Intestinal structure, pancreatic function, liver function and structure and a laparotomy all were normal. During the first 2 years of life BA levels in duodenal juice were consistently below the critical micellar concentration. In recent studies fecal BA were 7 times normal, serum $B A$ by radioimmanas ay failed to rise significantly after meals or after oral taurocholate and in duodenal juice, dihydroxy predominated over trihydroxy BA. Pool sizes of cholate and chenodeoxycholate, by isotope dilution were reduced to 6 and $23 \%$, serum cholate $\mathrm{T} \frac{1}{2}$ was $12 \%$ and chenodeoxycholate $7 \%$ of normal Vitamin B12 absorption (Schilling test) at age 4 years was normal These data lead us to conclude that our patient, who now thrives suffers from a specific congenital defect of ileal transport of bile acids causing a depleted BA pool and steatorrhea. This defect has not been reported previously.

\begin{tabular}{|c|c|c|c|c|}
\hline & $\begin{array}{l}\text { Total BA } \\
\text { Pool } \\
\left(\mathrm{mM} / \mathrm{m}^{2}\right)\end{array}$ & $\begin{array}{l}\text { Total BA } \\
\text { Synthes is } \\
\text { (mM } / \mathrm{m}^{2} / \text { day) }\end{array}$ & 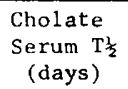 & $\begin{array}{l}\text { Chenodeoxy } \\
\text { Serum } \mathrm{T} \frac{1}{2} \\
\text { (days) }\end{array}$ \\
\hline Patient & 292 & 414 & 0.5 & 0.4 \\
\hline Control & 2148 & 299 & 3.9 & 3.1 \\
\hline
\end{tabular}
Oski), SUNY, Upstate Med Ctr, Dept of Peds, Syracuse It is generally believed that recurrent vomiting occurs with increased frequency among institutionalized retarded children. To test this hypothesis and to determine the causes of vomiting, we evaluated 136 pediatric residents of a school for the retarded. Recurrent vomiting (emesis > eight times per month) was present i 20 residents $(14.7 \%)$. Fifteen of the vomiters were evaluated by radiographic techniques, esophageal mannometry, upper intestinal endoscopy and esophageal acid reflux test (ART). GER was demonstrated by $x$-ray and/or ART in 11 of these 15 subjects $(73 \%)$. Of those with GER $10 / 11$ had occult blood in stool or emesis in the preceding year; $3 / 11$ were anemic $(\mathrm{Hg}<11.5 \mathrm{~g} \%$ ). Six had hiatal hernia. Five were said to be inducing emesis. Seven of 11 had resting lower esophageal sphincter pressure (LESP) $<15 \mathrm{~mm} H$, abnormal esophageal peristalsis and endoscopically demonstrated esophagitis. In the 4 patients with LESP > $15 \mathrm{mmHg}$, no esophagit is or abnormal peristalsis was present. The 11 patients with GER did not differ from the non-vomiting residents with respect to age ( 14.5 vs 13.9 yrs), incidence of seizures, spasticity or ability to walk. GER patients had significantly lower mental age (6.4 vs $16.6 \mathrm{mos}$ ) and higher incidence of kyphoscoliosis (54 vs $23 \%$ ). Onset of vomiting was after age 2 years in 9 of the 11 patients.

GER associated with a high incidence of hiatus hernia and esophagitis is common among retarded children who vomit. Vomiting appears later in life than in normal children with GER. Anatomic abnormalities accompanylng kyphoscollosis may contribute to the
473

ALTERED TASTE ACUITY IN CHILDREN WITH END-STAGE RENAI DISEASE (ESRD). Nancy S. Spinozzi, Christine L. and Warren E. Grupe. Department

Anorexia has been indicted qualitatively for the poor calorie intake commonly observed in children with ESRD. The contributing factors and the pathophysiology have not been clearly defined. Taste thresholds for salt( $\mathrm{NaCl}$ ), sour ( $\mathrm{HCl})$, sweet (sucrose), and bitter (urea) were quantitatively determined in 14 patients (age 8-18 years) on chronic hemodialysis and compared with 21 normal controls (ages 8-18 yrs). Detection thresholds for one or more tastants were elevated $>2$ S.D. above the normal mean in 12 of 14 patients pre-dialysis, while recognition thresholds were high in 9 of 14. Thresholds returned to normal in 5 following dialysis. Abnormal responses to sucrose and $\mathrm{HCl}$ were the most frequent; of the 9 with elevated recognition thresholds, all were abnormal to either sucrose or $\mathrm{HCl}$ while 5 were abnormal to both. petection for $\mathrm{NaCl}$ was elevated in 6 while recognition was high in only 3. Urea recognition was increased in only one patient. Caloric intake was $>10$ th percentile for age in 7 of the 14 patients compared to 3 of 9 with altered taste recognition. All patients with altered detection or recognition for both sucrose and $\mathrm{HCl}$ had caloric intakes $<10$ th percentile. Plasma $z$ inc levels were low in only two, both of whom had abnormalities of taste. Hypogeusia appears to be common in ESRD and may contribute to the anorexia characteristic of these children. Further understanding of taste acuity may permit specific alterations in dietary therapy which may alleviate some of this disability.

\section{MANAGEMENT OF ACUTE SECRETORY DIARRHEA SYNDROME (ASDS} 474 A. Strickland, G. Daoud, G. Ferry, W. Klish \& B. L. icine \& Texas Children's Hospital, Houston, TX 77030.

ASDS is a clinical syndrome characterized by frequent, watery stools, rapid onset of dehydration, and lack of response to diet. ary restriction. The stools are mainly yellowish water and are produced almost continuously. Stool electrolytes show sodium above $70 \mathrm{mEq} / \mathrm{L}$, chloride above $60 \mathrm{mEq} / \mathrm{L}$, and potassium below $30 \mathrm{mEq} / \mathrm{L}$. Diarrhea responsive to dietary restriction usually has sodium, potassium and chloride under $40 \mathrm{mEq} / \mathrm{L}$. Stool volhas sodium, potassium and chloride under $40 \mathrm{mEq} / \mathrm{L}$. Stool vol
umes in ASDA are over $60 \mathrm{cc} / \mathrm{kg} /$ day leading to rapid onset of dehydration, hyponatremia, and shock. Treatment with exclusively I.V. fluids for as long as 8 days has no effect on fecal losses in ASDS. In 1977, 28 cases of ASDS were recognized at Texas Children's Hospital. Oral colistin was of no value in ASDS. Parenteral aminoglycoside therapy was associated with recovery of normal stool patterns in 4 to 5 days. Oral gentamicin was associated with recovery of normal consistency, frequency, and electrolyte concentrations in 24 to 36 hours. Thus, ASDS is characterized by cholera-like stooling, dehydration during the first days of illness, and an elevated stool sodium. This synarome responds rapidly to oral gentamicin therapy.

Supported by Children's Clinical Research Center NIH RR-00188, Kelsey-Seybold Fellowship Fund and Venezuelan National Academy of Sciences. 